\title{
VIGILÂNCIA E PODER NA SALA DE AULA: AS INFLUÊNCIAS DO PANÓTIPO NO AMBIENTE DE ENSINO DE LÍNGUA ESTRANGEIRA
}

\author{
VIGILANCIA Y PODER EN LA SALA DE CLASES: LAS INFLUENCIAS \\ DEL PANÓPTIPO EN EL AMBIENTE DE ENSEÑANZA DE LENGUA \\ EXTRANJERA
}

\section{SURVEILLANCE AND POWER IN THE CLASSROOM: THE INFLUENCES OF THE PANOPTICON IN THE FOREIGN LANGUAGE TEACHING ENVIRONMENT}

\author{
Marina Rosa SEVERIAN ${ }^{1}$
}

\begin{abstract}
RESUMO: Sendo as escolas geralmente consideradas como panópticos, ao possibilitarem, por meio de suas arquiteturas, a vigilância de estudantes e professores, pressupõe-se que tal controle, supostamente ininterrupto possa desencadear diferentes efeitos de poder nas relações entre esses sujeitos. A fim de contemplar as influências da teoria do panóptico nas salas de aula de língua estrangeira, respaldo-me na teoria benthaniana e foucaultiana acerca do conceito de panóptico para discorrer sobre a forma como o poder e a vigilância podem ser estabelecidos em dois cenários distintos de sala de aula. A estrutura de ambos os espaços constitui-se em possibilidades diferentes de salas de aula na contemporaneidade. Tendo como base esses cenários, considero que a estrutura física da sala de aula pode ser um fator determinante para se exercer de maneira mais intensa ou sutil os efeitos de poder por meio da vigilância.
\end{abstract}

PALAVRAS-CHAVE: Ensino de língua estrangeira. Panóptico escolar. Vigilância. Poder.

RESUMEN: Considerando generalmente las escuelas como panópticos, al posibilitar, por medio de su arquitectura, la vigilancia de estudiantes y profesores, se presupone que dicho control, presuntamente sin interrupción, pueda desencadenar distintos efectos de poder en las relaciones entre esos sujetos. Con el objetivo de contemplar las influencias de la teoría del panóptico en las salas de clases de lengua extranjera, me respaldo en las teorías de Bentham y de Foucault acerca del concepto de panóptico para discurrir sobre la forma como el poder y la vigilancia pueden estar establecidos en dos escenarios distintos de sala de clases. La estructura de ambos los espacios se constituyen en posibilidades diferentes de salas de clases en la contemporaneidad. A partir de esos escenarios, considero que la estructura física de la sala de clases puede ser un factor determinante para ejercerse de manera más intensa o sutil los efectos de poder por medio de la vigilancia.

PALABRAS CLAVE: Enseñanza de lengua extranjera. Panóptico escolar. Vigilancia. Poder.

${ }^{1}$ Universidade Estadual Paulista (Unesp), Araraquara - SP - Brasil. Mestranda do Programa de Pósgraduação de Linguística e Língua Portuguesa. E-mail: mari.severian@gmail.com. 
ABSTRACT: Schools are generally considered panopticons, since they allow, through their architectures, surveillance of both learners and teachers. It is believed that this control, supposedly uninterrupted may trigger different effects of power in the relationship between these subjects. In order to look at the influences of panoptic theory in foreign language classrooms, we rely on the Benthanian and Foucaultian theory of the concept of panopticon to discuss how power and surveillance can be established in two distinct scenarios of classroom. Based on these scenarios, we believe that the physical structure of the classroom can be a determining factor to intensely or subtly maintain the effects of power through surveillance.

KEYWORDS: Foreign language teaching. Scholar panopticon. Surveillance. Power.

\section{O espaço educacional de línguas estrangeira como um panóptico}

O ambiente das salas de aula pode ser contemplado como estruturas propícias para a monitoração da disciplina e do poder por diversos sujeitos, como diretores, coordenadores, professores e, inclusive, pelos próprios estudantes. Não raro, diferentes escolas - regulares, especializadas em idiomas, universidades, etc. - apresentam salas de aula com estruturas físicas muito semelhantes entre si, como carteiras enfileiradas, visores de vidro nas portas, patamares onde os professores ministram suas aulas visualizando todos os alunos, e assim por diante. Tais características conspícuas de muitas salas de aula podem ser consideradas como recursos utilizados para inspecionar o que acontece dentro desse ambiente e também disciplinar os estudantes.

Além da estrutura física, a conduta social assumida pelos sujeitos também revela a maneira como o poder circula na classe influindo diretamente, segundo Foucault (1987), nos procedimentos disciplinares standard adotados ou impostos nesse ambiente, os quais tendem a restringir não apenas as ações realizadas, mas também os discursos veiculados no decorrer das aulas. Tais características estruturais e disciplinares remetem a um princípio arquitetônico, chamado por Jeremy Bentham de panóptico, como um recurso efetivo de vigilância em instituições onde pessoas são constantemente observadas por outros indivíduos, como ocorre em muitas salas de aula de língua estrangeira (doravante LE), por exemplo.

Contudo, deve-se ponderar o fato de que, na atual sociedade de controle, os moldes educacionais vêm sofrendo diversas mudanças, principalmente nas últimas décadas, não sendo sensato supor que as classes de língua estrangeira, que é o nosso escopo neste trabalho, sejam consideradas exatamente iguais como eram nos tempos em que a teoria do panóptico foi elaborada por Bentham, no século XVIII, e ressignificada 
por Foucault no final do século XX. De fato, percebemos que a estrutura física e as próprias condutas sociais no ambiente da sala de aula revelam, em algumas instituições educacionais, modificações no que se refere à disposição das carteiras e dos alunos, à presença progressiva de tecnologias - como circuitos internos de câmera de segurança, lousas digitais, tablets, etc. -, à relação estabelecida entre professores e estudantes, à forma como esses sujeitos ocupam tal espaço e, também, à sua arquitetura.

Tendo em vista que no contexto educacional de LE do século XXI coexistem diversos modelos de salas de aula, almejo desenvolver este trabalho respaldando-me concomitantemente nas teorias benthaniana e foucaultiana do panóptico como ponto de partida para discutir a maneira como a vigilância e o poder são estabelecidos em dois cenários distintos de sala de aula de LE. O projeto arquitetônico de ambos os espaços de ensino de LE está embasado em possibilidades de salas de aula (abordados ao longo da minha pesquisa de mestrado), as quais dispõem das seguintes estruturas físicas: i) uma sala de aula fechada com a tradicional disposição de carteiras enfileiradas, voltadas para o professor e para a lousa e ii) um ambiente aberto, sem lousa ou patamar para o professor, mas preenchido por mesas quadradas rodeadas por cadeiras e ocupadas tanto por estudantes quanto por professores.

Ao longo deste trabalho, apresento de maneira mais detalhada ambos os espaços mencionados acima, assim como discorro sobre possíveis influências estruturais para a prática da vigilância e do poder em cada um deles. Por se tratar de cenários tão distintos entre si e considerando a urgência de repensarmos os procedimentos de ensino de idiomas adotados até o presente momento, parto do pressuposto de que este estudo possa contribuir como fonte de reflexão no que se refere às estruturas - físicas e sociais - tradicionalmente adotadas pela escola, como instituição, e por nós, como professores de língua estrangeira, em relação aos nossos estudantes.

\section{A relação entre panóptico, vigilância e poder}

A concepção de panóptico foi empregada pelo filósofo utilitarista Jeremy Bentham, no final do século XVIII, para se referir a uma estrutura arquitetônica específica na qual, como a própria etimologia do termo revela, tudo e todos podem ser vistos. De acordo com o autor inglês, o panóptico trata-se de uma casa de inspeção que: 
Contém a ideia de um novo princípio de construção aplicável a qualquer tipo de estabelecimento, no qual pessoas são mantidas sob inspeção, particularmente em casas penitenciárias: prisões, abrigos, lazaretos, fábricas, hospitais, colônias de trabalho, manicômios e escolas com um plano de conduta (BENTHAM, 1843$, p. 37$)^{2}$.

Sendo assim, a teoria elaborada por Bentham propõe procedimentos de controle instaurados em diferentes instituições sociais, os quais são viabilizados por um projeto arquitetônico em comum, como forma de intensificar, por um lado, a contínua sensação de estar sendo observado e de garantir, por outro, a constante vigilância sobre as ações e os comportamentos dos indivíduos ocupantes desse espaço. Para que o projeto de inspeção ininterrupta em questão seja bem-sucedido, a teoria benthaniana propõe que os prédios institucionais sejam construídos conforme a seguinte estrutura:

Na periferia uma construção em anel; no centro, uma torre; esta é vazada de largas janelas que se abrem sobre a face interna do anel; a construção periférica é dividida em celas [...]; elas têm duas janelas, uma para o interior, correspondendo às janelas da torre; outra, que dá para o exterior, permite que a luz atravesse a cela de lado a lado. Basta então colocar um vigia na torre central, e em cada cela trancar um louco, um doente, um condenado, um operário ou um escolar (FOUCAULT, 1987, p. $165)$.

Segundo Bentham, a estrutura básica dos prédios institucionais é um recurso efetivo tanto para se observar as condutas dos ocupantes do espaço em questão a partir da área central quanto para se "obter poder de uma mente sobre a outra" (BENTHAM, 1843, p. 39). Com o intuito de atingir o efeito da vigilância e o do poder sobre os monitorados, o filósofo inglês propõe uma estrutura arquitetônica que os induza a acreditar ou a se sentir constantemente observados por um inspetor onipresente. Assim, tais indivíduos são condicionados a vivenciar uma permanente sensação de apreensão por julgarem estar sendo vigiados, ainda que ninguém esteja de fato os observando (STEADMAN, 2012, p. 16). Por meio dessa tática, os sujeitos monitorados sentem-se inevitavelmente coagidos a se autodisciplinarem.

${ }^{2}$ Todas as citações diretas retiradas de publicações em língua estrangeira foram traduzidas livremente pela autora deste artigo. 
Inegavelmente, tais artifícios disciplinares aliados à estrutura física do espaço e ao comportamento dos vigias inspiram o surgimento de uma espécie de entidade de poder onipresente e onisciente que não necessariamente está relacionada à figura de um indivíduo, mas sim, à de uma instituição. Segundo Pogrebinschi (2004, p. 192-194) essa é uma forma inovadora de poder disciplinar, exercido pelo aparelho institucional como um todo, e não apenas por um sujeito ou núcleo específicos, o qual se concretiza por meio de medidas normalizadoras e corretivas para coibir os transvios dos monitorados.

Nesse sentido, o panóptico vislumbrado por Jeremy Bentham não se refere somente à organização espacial de um edifício, pois vai além, almeja infiltrar-se no âmago dos sujeitos, prescrevendo os tipos de comportamentos que precisam ser normatizados e normalizados consoante os parâmetros estabelecidos pelas diferentes instituições sociais, como o próprio autor declara:

Para dizer tudo em uma palavra, isso será considerado aplicável, eu acredito que sem exceção, a todos os estabelecimentos de qualquer natureza, nos quais, dentro de um espaço não muito grande para ser controlado ou comandado a partir de edifícios, um número de pessoas deverá ser mantido sob inspeção. Não importa o quão diferentes ou mesmo opostos sejam os propósitos: quer seja o de punir o incorrigível, isolar o insano, reformar o viciado, confinar o suspeito, empregar o desocupado, manter os desamparados, curar o doente, instruir os interessados em qualquer ramo da indústria, ou treinar a raça em ascensão para o caminho da educação (BENTHAM, 1843, p. 40, grifo nosso).

Diferentemente de Bentham, Foucault (1987) problematiza os procedimentos e os efeitos do panoptismo nas instituições ao considerá-las como disciplinares pelo fato de induzirem o exercício e a perpetuação do poder, de modo velado, por meio de uma organização que intervém diretamente na conduta de cada sujeito. Ao mesmo tempo, esse dispositivo também visa segmentar os indivíduos do restante da sociedade, assim como dentro do próprio espaço institucional - ao separá-los em blocos e unidades específicos para cada grupo -, como uma maneira de não apenas estreitar o controle e a disciplinarização sobre os indivíduos, mas principalmente de conduzir o poder de forma automatizada e desindividualizada (FOUCAULT, 1995, p. 242; 1987, p. 167).

De acordo com Foucault (1987, p. 165), a segmentação dos indivíduos dentro das instituições passou a ser utilizada como um recurso de primeiramente identificar 
padrões para posteriormente classificar e distinguir os sujeitos conforme os seus graus de normalidade ou de anormalidade. Por meio dessa separação, torna-se possível modificar ou mesmo moldar o comportamento disciplinar dos indivíduos considerados anormais, ou que não se encaixam em um parâmetro previamente estabelecido pela instituição, viabilizando que condutas padronizadas sejam progressivamente instauradas nesse espaço como forma de disciplinarização.

Considerando os aspectos de segmentação, classificação e organização dos indivíduos, Foucault (1987) contempla o panoptismo como um mecanismo muito eficiente de inspeção pelo fato de visar remodelar persistentemente as condutas de cada um, desvelando-se, portanto, “como uma espécie de laboratório de poder”:

Encontramos no programa do Panóptico a preocupação análoga da observação individualizante, da caracterização e da classificação, da organização analítica da espécie. O Panóptico é um zoológico real; o animal é substituído pelo homem, a distribuição individual pelo agrupamento específico e o rei pela maquinaria de um poder furtivo. [...] Por outro lado, o Panóptico pode ser utilizado como máquina de fazer experiências, modificar o comportamento, treinar e retreinar os indivíduos (FOUCAULT, 1987, p. 168).

Diante do exposto, nota-se que o dispositivo do panóptico correspondia a um mecanismo verossímil para se manter a vigilância, o poder e a disciplinarização nos séculos passados, contudo, no cenário contemporâneo, a sua aplicação não se mostra tão coerente ou eficiente como Bentham havia proposto e Foucault, criticado. Segundo Bauman (2001, p. 18): “o que importava no Panóptico era que os encarregados 'estivessem lá', próximos da torre de controle”, e hoje os indivíduos que detêm o poder "podem fugir do alcance a qualquer momento - para a pura inacessibilidade".

Embora hoje o panóptico aparente ter sido superado, compreendo que os seus embasamentos e as suas inovações tenham influenciado sobremaneira o modo como as instituições contemporâneas se organizam e utilizam os recursos de vigilância e poder suscitados por tal mecanismo disciplinar. Considerando, portanto, que o chamariz desse projeto seja a sua notável aplicabilidade em diversas instituições e situações, abordo a seguir o seu emprego no contexto educacional e, mais adiante, no de LE.

\section{O panóptico escolar}


Ao contemplar o panóptico em instituições de ensino, Bentham (1843, p. 62-66) propõe a aplicação da arquitetura base, apresentada anteriormente, nos diferentes ambientes escolares - de aprendizagem e também de descanso -, a fim de intensificar a ocupação dos alunos exclusivamente com os estudos por meio da inspeção contínua de suas atividades. Os procedimentos de vigilância adotados na escola visam moldar a conduta dos estudantes de modo que cada indivíduo sob inspeção "se comporte de maneira socialmente esperada ou desejada e que a correção, ou punição, das ações sirva de exemplo para os demais" (MARQUES, 2013, p. 7).

Bentham julgava que as práticas fiscalizadoras e corretivas implementadas por meio do panóptico escolar contribuiriam para a formação de cidadãos devido à ênfase em se seguir parâmetros éticos e morais voltados para o bem-estar social e econômico. A partir dessas práticas estabelecidas no âmbito educacional, inicia-se um movimento cujo intuito é o de disciplinar os indivíduos ocupantes desse espaço por meio de uma configuração social, alicerçada na relação entre professores e alunos, e a qual influi na produção tanto do poder quanto dos corpos dóceis.

Nessa relação, os professores ocupam a posição de responsáveis pela inspeção e correção disciplinar, uma vez que, segundo Bentham (1843, p. 63), a simples presença de sua figura "central e protegida" tende a desencorajar de imediato quaisquer tipos de conversa, brincadeira ou distrações por parte dos estudantes. Sendo assim, o autor inglês sugere que o professor seja onipresente e ocupe uma posição de destaque no que se refere à vigilância dentro da instituição de ensino pelo fato de ser o incumbido pela orientação intelectual dos seus alunos: "a sua mente (de um menino) será fruto da mente do seu mestre" (BENTHAM, 1843, p. 64). Aliado a esse fator, o uso de divisórias entre os alunos visa coibir ações desvinculadas ao estudo, assim como reforçar tanto a posição de prestígio e autoridade do professor quanto a docilização dos corpos dos estudantes (PRATA, 2005, p. 109).

Cada um, em seu lugar, está bem trancado em sua cela de onde é visto de frente pelo vigia; mas os muros laterais impedem que entre em contato com seus companheiros. É visto, mas não vê; objeto de uma informação, nunca sujeito numa comunicação. [...] Esta é a garantia da ordem. [...] (Se são) crianças, não há "cola", nem barulho, nem conversa, nem dissipação (FOUCAULT, 1987, p. 166). 
Embora Jeremy Bentham julgasse que as aplicações do panóptico no ambiente escolar pudessem surtir efeitos benéficos à sociedade como um todo, Foucault (1987) concebeu-as como uma maneira funesta de se endossar o exercício do poder ao inculcar nos estudantes um contínuo estado de alerta e consciência referente à vigilância. Por meio desses procedimentos disciplinares, a implementação do panóptico nos espaços escolares tende a produzir um contingente de indivíduos condicionados a se ocuparem exclusivamente com os estudos, ao passo que são impelidos a agirem e a reagirem de um modo determinado por comportamentos standards, os quais não representam, necessariamente, as expressões reais de si mesmos.

Em relação a isso, Foucault (1987) concebe que os alunos sob inspeção dentro de uma instituição escolar são condicionados a seguir condutas padronizadas como forma não apenas de se encaixarem no meio social em que estão inseridos, mas também de serem compelidos a docilizar seus corpos por meio de um processo disciplinar:

O corpo humano entra numa maquinaria de poder que o esquadrinha, o desarticula e o recompõe. Uma "anatomia política", que é também igualmente uma "mecânica do poder", está nascendo; ela define como se pode ter domínio sobre o corpo dos outros, não simplesmente para que façam o que se quer, mas para que operem como se quer, com as técnicas, segundo a rapidez e a eficácia que se determina. A disciplina fabrica assim corpos submissos e exercitados, corpos "dóceis" [...] Encontramo-los em funcionamento nos colégios, muito cedo; mais tarde nas escolas primárias (FOUCAULT, 1987, p. 119).

Segundo a perspectiva foucaultiana, a oportunidade de se produzir corpos dóceis por meio de instituições disciplinares é uma maneira eficiente de se exercer o poder social pelo fato de não ser oneroso, economicamente falando, e atribuir uma utilidade tanto a quem inspeciona - o professor - quanto a quem é inspecionado - os estudantes (PRATA, 2005, p. 110). Em ambos os casos, é patente que os indivíduos envolvidos nessa equação estejam subjugados ao domínio e ao poder institucionais sem que necessariamente o percebam, ou seja, o aparelho escolar cria procedimentos de controle e poder ao outorgar funções específicas e distintivas a cada sujeito, de modo que se tornem peças fundamentais nessa engrenagem de vigilância e poder.

Embora o regime de poder dessa sociedade disciplinar almejasse exercer o controle e a docilização plena nos corpos dos indivíduos dentro das instituições sociais, 
alguns autores (HARDT E NEGRI, 2001 e DELEUZE, 1992) questionam a total efetividade de tais procedimentos em virtude de suas aplicações se restringirem apenas ao interior desses espaços. Diante disso, não se torna possível, nem factível afirmar que tais comportamentos realmente se manifestassem fora dos limites institucionais de maneira automática ou espontânea justamente por não haver a continuidade desses procedimentos no corpo social como um todo.

Inclusive, no caso das escolas inseridas nessa sociedade disciplinar, a vigilância constante por meio do modelo do panóptico pretendia incutir nos estudantes uma necessidade de autocorrigirem as suas condutas, porém o controle exercido não era profundo o bastante para de fato se arraigar nos seus corpos e consciências como almejava a teoria de Bentham (PANIAGO E FERNANDES, 2013, p. 71). Com isso, desvelou-se que o regime de poder de cunho disciplinar tornou-se não apenas insuficiente, mas principalmente ineficaz na sociedade pós-Segunda Guerra, posto que o sucesso de se exercer o controle sobre os demais dependia exclusivamente de espaços institucionais fechados e ações de enclausuramento, os quais divergiam da perspectiva e das necessidades econômico-sociais nesse momento histórico-social.

A partir dessa perspectiva, iniciou-se um movimento de mudanças sociais necessidade de ascender socialmente e se libertar do confinamento - e econômicas expansão do capitalismo - que viabilizaram a transição, ou o atravessamento, da sociedade disciplinar para a sociedade de controle, a qual é:

Marcada pela interpenetração dos espaços, por sua suposta ausência de limites definidos (a rede) e pela instauração de um tempo contínuo no qual os indivíduos nunca conseguiriam terminar coisa nenhuma, pois estariam sempre enredados numa espécie de formação permanente, de dívida impagável, prisioneiros em campo aberto (COSTA, 2004, p. 161).

Especificamente no âmbito escolar, a ascensão da sociedade de controle vem inspirando mudanças de ordem organizacional ao contemplar a dispensabilidade do confinamento dos estudantes nesses espaços - franqueando possibilidades para o surgimento de metodologias educacionais e de escolas menos conservadoras - e a necessidade de dar continuidade ao crescimento social e profissional por meio da formação permanente. O propósito de se incutir na sociedade a perspectiva de urgência quanto à perenidade de se obter mais conhecimentos e alcançar melhores graduações 
relaciona-se à crescente competitividade profissional, cuja base pode estar alicerçada na concepção de meritocracia ${ }^{3}$ : apenas obtém sucesso quem é competente ou se dedica.

Por essa razão, há a tendência de aproximação entre escolas e empresas, dando seguimento ao processo de formação permanente como modo de ascensão pessoal e profissional ao preparar os estudantes, desde cedo, para se adaptarem à realidade competitiva do mundo do trabalho em uma sociedade capitalista e de controle. A partir dessa percepção, a circulação do poder passou a ser diferente nas instituições sociais, inclusive nas escolas, uma vez que a dominação dos corpos não era o suficiente para se instaurar um regime altamente produtivo para o cenário capitalista, sendo necessário, portanto, que a vida dos indivíduos se tornasse administrável, como um objeto de poder (HARDT E NEGRI, 2001, p. 43).

Embora as práticas de controle nesse paradigma tenham se mostrado mais eficientes e recorrentes nas abordagens institucionais e educacionais das escolas, considero que o modelo disciplinar não tenha simplesmente se dissipado diante da sociedade de controle, pelo contrário, ele continua agindo e produzindo efeitos de poder nesse meio junto com os procedimentos de controle. Diante desse entrelaçamento entre os paradigmas de poder, torna-se pertinente questionar se a aplicação do panóptico escolar em nossa sociedade contemporânea ainda tem lugar e qual seria a sua função nesse contexto permeado pela disciplina e, principalmente, pelo controle.

Em relação a isso, Veiga-Neto (2001, p. 18) pondera a contingência de o princípio do panóptico não ser mais interessante ou mesmo aplicável nas instituições escolares pelo fato de tanto a perspectiva de produção e acumulação capitalistas quanto a tecnologização dos mecanismos de vigilância e controle social terem conduzido a nossa sociedade para um estado contínuo de vigilância extrainstitucional:

Talvez não seja mais necessário que a escola panóptica seja o lugar pelo qual devam passar todas as crianças a fim de aprenderem a viver nos espaços e nos tempos em que o mundo quer colocá-las. Com isso, eu não quero dizer algo como "finalmente, estamos livres do poder disciplinar". Meu argumento vai em outra direção: talvez não precisemos mais da escola como máquina panóptica simplesmente porque o próprio mundo se tornou uma imensa e permanente máquina panóptica.

3 Segundo Fischer (1998, p. 747), a meritocracia é "o poder da inteligência que, nas sociedades industriais, estaria substituindo o poder baseado no nascimento ou na riqueza, em virtude da função exercida pela escola". 
Nesse sentido, Veiga-Neto pretende alertar que os princípios do panoptismo na educação extrapolaram as barreiras institucionais escolares, de modo que se instalaram na sociedade como um todo, ampliando ainda mais os territórios do controle por meio de efeitos de poder que transpassam as práticas disciplinares ao agirem não apenas nos corpos dos indivíduos, mas infundindo em suas consciências. Enquanto Veiga-Neto (2001) pondera que o mundo se tornou um mecanismo panóptico, pois tal recurso vem sendo aprimorado pela tecnologia e se tornou globalizado, Gallagher (2010) concebe que as técnicas de vigilância ultrapassaram os princípios do panoptismo por serem mais complexas e confusas do que se havia imaginado, contemplando-os restritamente no âmbito educacional.

Com base na perspectiva de que o panoptismo foi suplantado por outras formas de monitoramento, Gallagher (2010, p. 266) afirma que "a vigilância na escola era profundamente descontínua, em contraste com o panóptico ideal de total e constante visibilidade e frequentemente ocorria tanto pela audição quanto pela visão". Levando em consideração os argumentos apresentados até o momento, pondero que estamos acompanhando, neste momento histórico-social, uma simultânea expansão e superação do panoptismo no âmbito escolar, uma vez que tal princípio está de fato transpondo os muros institucionais, ao passo que também está sendo sobrepujado por outras modalidades de vigilância intra e extrainstitucionais, as quais visam controlar os indivíduos no seu todo (corpo, consciência e alma).

Nessa perspectiva, a teoria do panóptico tornou-se uma forte influência e uma rica fonte de inspiração para que procedimentos educacionais pautados não apenas no controle, mas também na disciplinarização, outorgassem à escola uma importância inestimada no que se refere à organização social. Isso ocorre devido ao fato de as escolas representarem uma instituição responsável por orientar a sociedade em geral a atingir o ápice da sua produtividade e do seu controle, já que as mesmas são incumbidas a iniciar os indivíduos no processo da permanente formação.

Contemplando, assim, as discussões suscitadas ao longo deste trabalho acerca dos efeitos do panóptico nas instituições escolares da atual sociedade de controle, considero relevante refletir sobre a aplicação de tais efeitos no contexto específico do ensino de línguas estrangeiras. Dessa maneira, volto meu olhar para dois espaços distintos de sala de aula de LE a fim de discorrer sobre as influências do panoptismo e, portanto, das estruturas arquitetônicas de ambos esses ambientes na implantação da vigilância e na circulação do poder. 


\section{Influência do panóptico nos cenários de ensino de LE}

De acordo com as discussões anteriores, a concepção e também a utilização do panóptico no cenário educacional oportunizaram a aplicação de procedimentos de vigilância e controle como formas de se obter e manter o poder tanto no espaço das salas de aulas quanto fora das instituições escolares, considerando que as mesmas estão inseridas em uma sociedade de controle. Refletindo especificamente sobre o ambiente de ensino de língua estrangeira, concebo que, com o advento da sociedade de controle, a acentuada expansão da tecnologização e da globalização vem impelindo os indivíduos a buscar o domínio de uma segunda língua como forma de darem continuidade ao processo de formação permanente e, consequentemente, de obterem maiores chances de alcançar o sucesso profissional (BULLIO; DEL-RÉ, 2010, p. 3).

Assim, o crescimento da demanda por escolas de idiomas nas últimas décadas impulsionou, por um lado, o estabelecimento de um mercado promissor de ensino de idiomas e, por outro, o aprimoramento das salas de aula como forma de aliar o avanço tecnológico às práticas de ensino e de sanar as necessidades do público interessado em aprender outras línguas. Sendo assim, tornou-se fundamental estabelecer tanto nas escolas regulares quanto nas especializadas em idiomas espaços de ensino condizentes não apenas com o processo de desenvolvimento da tecnologização e globalização, mas principalmente, com a sociedade de controle na qual nos inserimos.

Nesse contexto, as salas de aula de LE podem revelar-se ambientes onde as práticas disciplinares de vigilância corroborem para que a circulação do poder ocorra em diferentes direções - verticalizada e também horizontalizada - e não seja, necessariamente manifesto ou mesmo localizável (BRAGA, 2014, p. 66). Isso acontece no cenário de ensino de idiomas em virtude de os procedimentos de controle e poder se mostrarem potencializados quando o enclausuramento, proposto pela sociedade disciplinar, transforma-se em percepção de liberdade, ainda que a mesma seja apenas aparente. Assim, as salas de aula alicerçadas em estruturas físicas as quais passam a sensação de confinamento podem não ser tão eficientes para controlar e permitir a circulação do poder de maneira mais eficiente do que em um ambiente que seja menos aprisionante (SEVERIAN, 2016).

A coexistência desses diferentes espaços de ensino de LE, no que se refere às suas estruturas físicas e arquitetônicas, pode revelar se as mesmas intensificam ou amenizam os procedimentos de vigilância e poder entre professores e alunos. Dessa 
maneira, o planejamento da estrutura física e arquitetônica de uma sala de aula pode ser utilizado como um recurso para vigiar, disciplinar e, portanto, controlar o comportamento de professores e alunos. Esse comportamento, por sua vez, pode ser visivelmente sugestionado pela arquitetura e disposição da sala de aula e, obviamente, pelas imposições normativas da instituição de ensino, possibilitando que diferentes formas de vigilância e poder sejam estabelecidas.

Muitas instituições regulares e especializadas em idiomas baseiam-se em classes consideradas tradicionais, isto é, ambientes fechados preenchidos com carteiras enfileiradas as quais estão direcionadas para frente da sala, onde estão a mesa do professor, a lousa e, no contexto atual, aparatos tecnológicos, como computador e datashow. Um modelo muito característico desse tipo de sala de aula está representado na figura 1 abaixo:

Figura 1: Planta da sala de aula em espaço fechado

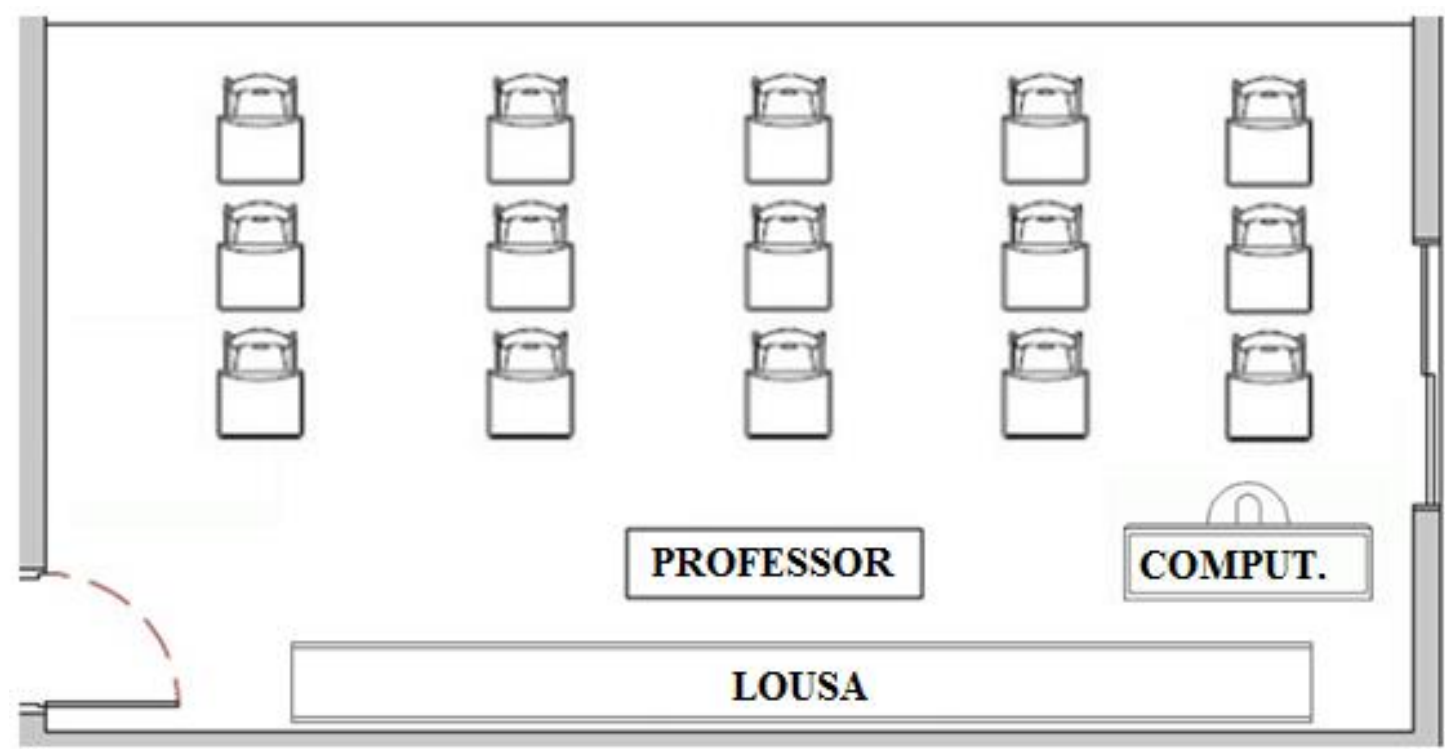

Fonte: Elaboração própria

O modelo ilustrado acima é provavelmente o mais recorrente nas instituições escolares brasileiras e o qual geralmente é assimilado a um espaço de ensino e aprendizagem por diferentes indivíduos que frequentaram ou ainda frequentam um colégio. Tal realidade não é diferente no contexto de LE, uma vez que as salas de aulas tendem a ser espaços fechados, com a presença de algumas janelas e portas, onde a disposição das carteiras pode variar de acordo com a escola, mas tradicionalmente são colocadas exatamente como consta na figura 1. 
No que se refere à questão da vigilância nesse tipo de sala de aula de LE, pondero que muitas escolas tendem a preservar essa estrutura física pelo fato de enfatizar a importância da figura do professor em relação à dos estudantes ao lançarem mão de recursos que ratificam tal percepção, como, por exemplo, a mesa centralizada em frente às carteiras dos alunos. É interessante ressaltar que além dessa característica referente à mesa do docente, algumas salas de aula também possuem uma espécie de patamar que se conecta à parede em que a lousa está localizada, portanto na parte frontal da classe, o qual funciona como uma espécie de torre moderna do panóptico, pelo fato de permitir ao professor uma visão privilegiada e geral dos alunos.

Ambos os mecanismos apresentados acima operam em prol da fiscalização total dos estudantes além de reforçarem o papel de autoridade do professor na sala de aula, os quais podem ser interpretados como resquícios de práticas disciplinares propostas pelo panoptismo, uma vez que todos os estudantes podem ser inspecionados e estão subjugados pelo olhar do docente. Além disso, no âmbito de LE, tais recursos também podem influir de maneira pejorativa no que se refere ao distanciamento entre professores e alunos pelo fato de servirem, primeiramente, como uma maneira de limitar o território que cabe a cada um desses indivíduos e, também, de destacar o espaço pertencente ao docente em virtude do seu grau de conhecimento linguístico no idioma estrangeiro em relação com o dos estudantes, como ressalta Narezzi (1998, p. 30):

É um padrão já de longa tradição na Educação, que tem por centro o discurso do professor e mantém uma distinção nítida dos papéis de seus participantes. Ao professor é atribuído o papel de dominador, enquanto que aos alunos, o de subordinados. Na sala de aula de línguas, esta assimetria pode ser mais claramente delineada pela desigualdade linguística entre professor e aluno, em torno da qual as atividades se desenvolvem.

Nesse caso, torna-se perceptível que a circulação do poder no âmbito da sala de aula apresentada na figura 1 é reforçada tanto por regulações institucionalizadas referentes ao saber de cada indivíduo como pela presença destacada e centralizada do professor. A partir dessa estrutura, pondero que a intenção da escola como instituição é a de justamente explicitar quem detém o controle e o poder no espaço de ensino e aprendizagem de LE. Contudo, não se pode ignorar o fato de principalmente as escolas de idiomas estarem revendo as suas salas de aula com o intuito de oferecerem aos 
estudantes um espaço mais aconchegante e menos claustrofóbico do que o expresso na figura 1.

Contemplando uma dentre inúmeras possibilidades de espaços de ensino, apresento abaixo um modelo (figura 2) que chamarei de aberto por não ser necessariamente uma sala de aula per se:

Figura 2: Planta da sala de aula em espaço aberto

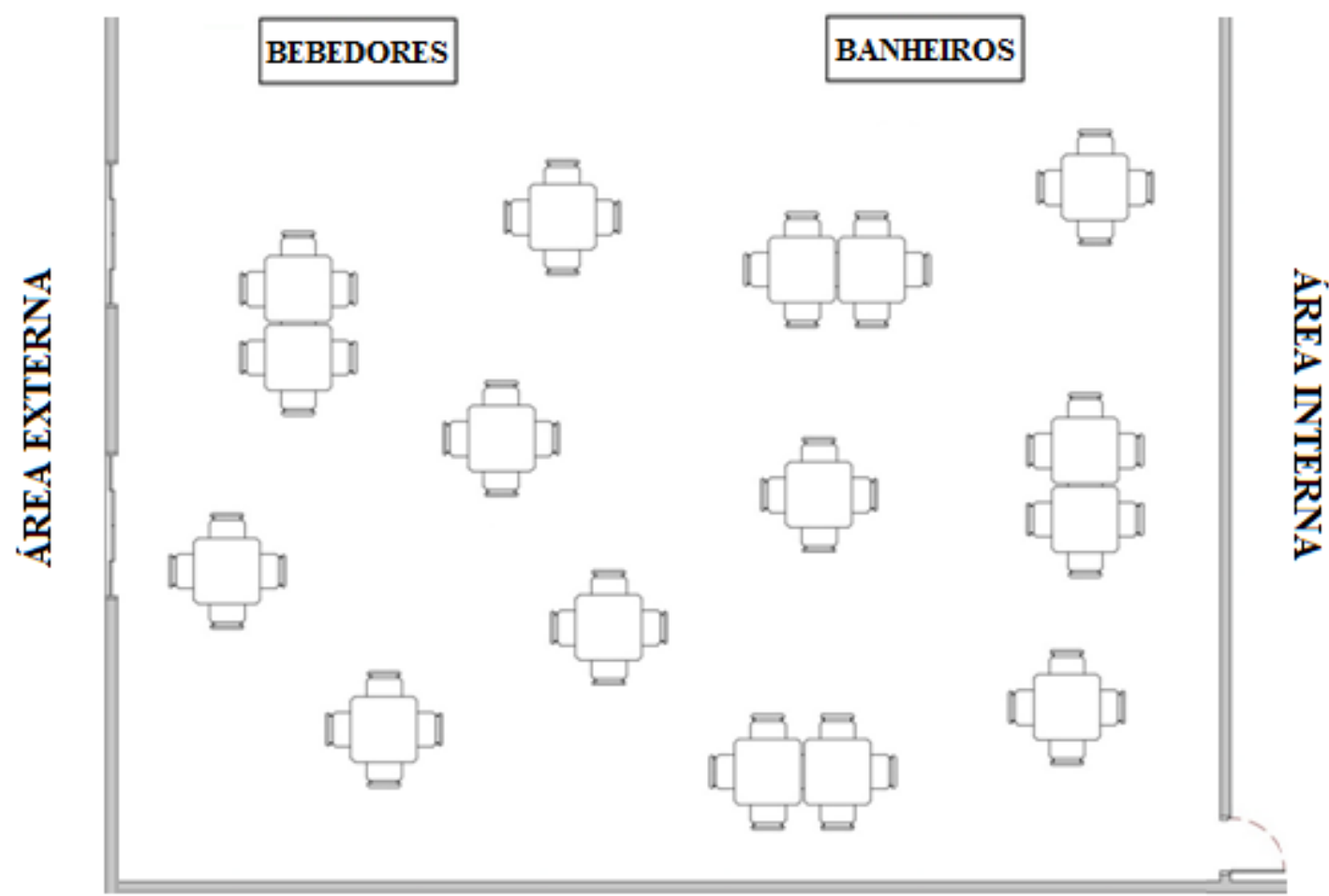

Fonte: Elaboração própria

Como é possível observar no modelo ilustrado na figura 2, a classe pode ser considerada relativamente aberta - embora seja coberto, o ambiente é amplo e possui, dentro de sua área, espaço para bebedores e banheiros -, de modo que não há paredes separando ou divisórias que seccionem tal espaço em áreas menores. Além disso, algo que chama atenção nessa segunda imagem refere-se à ausência de alguns recursos característicos das salas de aula - como lousa, mesa exclusiva do professor, carteiras enfileiradas, computador e recursos tecnológicos -, os quais geralmente são encontrados na maioria das salas de aula tradicionais, como é possível observar na figura 1.

Outra questão muito interessante observada na sala de aula aberta é o fato de o seu espaço ser preenchido por mesas maiores, utilizadas e compartilhadas tanto por 
estudantes quanto pelo professor, cuja disposição permite interação direta entre esses indivíduos, sem que o docente ocupe, necessariamente, o lugar de destaque no ambiente de aprendizagem. Além disso, essas mesas estão distribuídas de maneira irregular, sem que estejam enfileiradas ou voltadas para a direção do docente, o que revela certo afastamento em relação à organização estrutural rígida e emblemática encontrada no panoptismo escolar benhtaniano.

Assim, considero que o modelo de sala de aula de LE representado na figura 2 esteja mais próximo do que a sociedade de controle propõe para o cenário institucional de ensino, a qual encoraja a ruptura do confinamento espacial a fim de fomentar nos indivíduos a sensação de leveza e liberdade para permanecer na constante busca pela formação. Nesse espaço, a aprendizagem da língua estrangeira pode acontecer de maneira menos impositiva, por não haver paredes atuando em prol da predominância do poder vertical, possibilitando que as discrepâncias do conhecimento linguístico sejam minimizadas.

Contudo, é necessário ter cuidado e ficar atento às armadilhas que o regime de poder baseado no controle utiliza para, simultaneamente, transparecer maior liberdade e intensificar a circulação do poder na classe de LE. Isso significa dizer que, apesar de os alunos e os professores se sentirem provavelmente mais livres e confortáveis nesse espaço aberto de ensino e aprendizagem, é nítido que essa estrutura física oportunize um tipo de vigilância ainda mais acentuado do que o da figura 1 em razão de a inspeção ser realizada por todos os indivíduos ocupantes desse ambiente.

Retomando Veiga-Neto (2001), a sociedade de controle encontrou meios que possibilitaram expandir a atuação do panóptico - antes restrito às áreas segmentadas da instituição escolar - para dimensões mais globais, acentuando, por um lado, os mecanismos de poder e de vigilância, mas mitigando, por outro, a sensação de confinamento e interdição ao longo das aulas de língua estrangeira. Sendo assim, se no primeiro modelo apresentado a vigilância aparenta se concentrar predominantemente nas mãos do docente - embora muitos alunos também contribuam para a perpetuação desse sistema de fiscalização -, neste último tipo de sala de aula, tanto os alunos e professores que compartilham uma mesa quanto os ocupantes de outras estão livres para observar as condutas dos demais, podendo interditá-los, recriminá-los ou delatá-los (MASCIA, 2003).

Essa aparente transparência pode desvelar, portanto, um sistema de poder extremamente sutil, porém ainda mais capcioso quando comparado com os mecanismos 
representados na figura 1, os quais se mostram, ou ao menos parecem ser, mais evidentes. $\mathrm{O}$ fato de as carteiras serem compartilhadas nesse segundo modelo também é algo importante, pois a sensação é a de aproximação entre os indivíduos - ainda que estejam o tempo todo observando e sendo observados. Ao passo que, na primeira figura, as carteiras são individuais e remetem à impressão de restrição de conduta, indicando que cada indivíduo deve se manter na sua carteira e se ocupar com os próprios estudos sem que lhe seja permitido interagir, tornando o processo de aprendizagem em algo individualista e, talvez, pouco comunicativo.

Pondero que a arquitetura e a disposição das mesas na segunda imagem sejam pontos favoráveis para que diferentes tipos de metodologia de se ensinar LE - baseadas em projetos, tarefas, comunicativas, discursivas, etc. - sejam implantadas, em virtude de o próprio espaço promover a possibilidade de maior interação e participação ativa entre os indivíduos envolvidos nesse processo de ensino e aprendizagem. A partir dessa perspectiva, as classes de LE poderiam se revelar mais interessantes e significativas para os estudantes, uma vez que possa haver maior possibilidade de os mesmos participarem ativamente da construção do conhecimento junto dos professores (LEFFA, 2005). Visto que, nas aulas tradicionais de LE, segue-se um padrão muito recorrente nos modelos estruturais representados pela figura 1 de os professores geralmente se posicionarem na frente da sala para ministrar as preleções enquanto os estudantes ocupam o papel de espectadores passivos, sentados em suas carteiras sem que lhes seja outorgado espaço suficiente para maior participação.

\section{Considerações finais}

Ao associar a imponência das estruturas arquitetônicas escolares com a eficácia dos mecanismos disciplinares, a teoria do panóptico na educação constituiu-se em uma forma de viabilizar a circulação do poder em espaços de sala de aula regularmente monitorados pelo professor, de modo que os estudantes se sentissem constantemente sujeitos à vigilância e ao controle institucional. No cenário de ensino de LE, é possível encontrar diferentes tipos de estruturas de classes coexistentes em escolas regulares ou especializadas em idioma na contemporaneidade, as quais ora revelam forte influencia do panoptismo, ora parecem se afastar de tal princípio de poder.

Embora os modelos de sala de aula de LE apresentados neste trabalho possuam arquiteturas e estruturas físicas muito divergentes entre si, tornou-se perceptível que o 
espaço fechado (figura 1) retome os recursos e mecanismos descritos por Bentham (1843) e problematizados por Foucault (1987) no que se refere às práticas disciplinares e de controle por meio tanto da vigilância quanto da presença marcante e autoritária do professor. Dessa maneira, considero que esse modelo de sala de aula de LE corrobore para a circulação de um poder predominantemente verticalizado - o qual flui na direção da autoridade, professor, para os subjugados, alunos -, permitindo que o controle seja exercido de maneira contínua sobre os corpos dos estudantes, devido à disposição organizacional de suas carteiras em relação à do docente.

Contudo, com a ascensão da sociedade de controle, as práticas disciplinares baseadas no confinamento do indivíduo em espaços físicos pré-determinados, assim como a dissolução da visibilidade e, também, da consciência de se estar sendo vigiado possibilitaram a aparente percepção de liberdade em relação às condutas de alunos e professores ao longo das aulas. Tais artifícios podem ser assimilados à estrutura da sala de aula aberta (figura 2) pelo fato de não haver divisões claras entre os estudantes, em si, e também entre o professor de LE, de modo que a consciência e os corpos de ambos esses indivíduos sejam sugestionados pela suposta sensação de liberdade, permitindo, contrariamente, que o controle se intensifique de maneira dissimulada por meio da dissipação do poder nesse espaço institucional.

Por fim, pondero que os diferentes modelos existentes de sala de aula de língua estrangeira não estejam livres, tampouco estejam os indivíduos que os ocupam, das práticas disciplinares e de controle legitimadas pela sociedade contemporânea, de modo que é possível percebê-las tanto nos pequenos - porém extremamente significativos detalhes referentes à disposição da estrutura escolar quanto na distribuição dos estudantes e professores nesses espaços de ensino. Assim, a partir desses procedimentos sociais e arquitetônicos propostos pelo panoptismo, compreendo que os mecanismos de vigilância instaurados nas instituições escolares tendem a operar em prol da ratificação do poder nas classes de LE.

\section{REFERÊNCIAS}

BAUMAN, Z. Modernidade líquida. Rio de Janeiro: Jorge Zahar, 2001.

BENTHAM, J. Panopticon or the inspection-house. In: BOWRING, J. (ed.) Works of Jeremy Bentham. Edinburgh: Tait, p. 37-172, 1843. 
BRAGA, M. D. W. O discurso sobre o livro didático de inglês: a construção da verdade na sociedade de controle. 2014, 246 f. Trabalho de Tese de Doutorado Universidade de São Paulo, Faculdade de Filosofia, Letras e Ciências Humanas, São Paulo, 2014.

BULLIO, P. C.; DEL-RÉ, A. A interação na sala de aula de língua estrangeira. Revista Signo, Santa Cruz do Sul, v. 35, n. especial, p. 02-39, jul./dez. 2010.

COSTA, R. Sociedade de controle. São Paulo em Perspectiva, v. 18, n. 1, São Paulo, p. 161-167, jan./mar. 2004.

DELEUZE, G. Post-scriptum sobre as sociedades de controle. In: DELEUZE, G. Conversações. São Paulo: Editora 34, p. 219-226, 1992.

FISCHER, L. Meritocracia. BOBBIO, N.; MATTEUCCI, N.; PASQUINO, G.

Dicionário de política. 11 ed. Trad. Carmem C. Varrialle et al. Brasília: Editora da Universidade de Brasília, vol. 1, p. 747-748, 1998.

FOUCAULT, M. Vigiar e punir. Petrópolis: Vozes, 1987.

FOUCAULT, M. O sujeito e o poder. In: DREYFUS, H.; RABINOW, P. Michel Foucault - uma trajetória filosófica: para além do estruturalismo e da hermenêutica. Rio de Janeiro: Forense Universitária, p. 231-249, 1995.

GALLAGHER, M. Are schools panoptic? Surveillance \& Society, v. 7, n. 3/4, p. 262$272,2010$.

HARDT, M.; NEGRI, A. Império. 2a ed. Rio de Janeiro: Record, 2001.

LEFFA, V. J. O professor de línguas estrangeiras: do corpo mole ao corpo dócil. In: FREIRE, M. M.; ABRAHÃO, M. H. V.; BARCELOS, A. M. F. (Org.). Linguística Aplicada e contemporaneidade. São Paulo: ALAB/Pontes, 2005, p. 203-218.

MARQUES, S. C. M. Bentham e a educação: um projeto social. Educação Temática Digital, Campinas, v. 15, n. 1, p. 1-15, jan./abr. 2013.

MASCIA, M. A. A. Investigações discursivas na pós-modernidade: uma análise das relações poder-saber do discurso político educacional de língua estrangeira. Campinas: Mercado de Letras/Fapesp, 2003.

NAREZZI, E. C. O poder em sala de aula: disputas, amenização e sedução. 1998, 131f. Trabalho de Dissertação de Mestrado - Universidade Estadual de Campinas, Instituto de Estudos da Linguagem, Campinas, 1998.

PANIAGO, M. L. F. S; FERNANDES, E. M. F. O corpo educado: a escola como dispositivo disciplinador na sociedade de controle. Revista Eletrônica de Estudos do Discurso e do Corpo, Vitória da Conquista, v. 4, n. 2, p. 68-77, 2013. 
PRATA, M. R. S. A produção da subjetividade e as relações de poder na escola: uma reflexão sobre a sociedade disciplinar na configuração social da atualidade. Revista Brasileira de Educação, n. 28, p. 108-115, jan./abr. 2005.

POGREBINSCHI, T. Foucault, para além do poder disciplinar e do biopoder. Revista Lua Nova, n. 63, p. 179-201, 2004.

SEVERIAN, M. R. Relações de poder em uma escola pautada nas singularidades: olhares sobre as práticas de língua estrangeira. 2016, 253 f. Trabalho de Dissertação de Mestrado - Universidade Estadual Paulista "Júlio de Mesquita Filho", Faculdade de Ciências e Letras, Araraquara, 2016.

STEADMAN, P. Samuel Bentham's Panopticon. Journal of Bentham Studies, v. 14, p. 1-30, 2012.

VEIGA-NETO, A. Espaços, tempos e disciplinas: as crianças ainda devem ir à escola? In: CANDAU, V. M. (Org.). Linguagens, espaços e tempos no ensinar e aprender. Rio de Janeiro: DP\&A Editora, 2001. p. 9-20.

\section{Como referenciar este artigo}

SEVERIAN, Marina Rosa. Vigilância e poder na sala de aula: as influências do panóptico no ambiente de ensino de língua estrangeira. Rev. EntreLínguas, Araraquara, v.3, n.1, p. 75-94, jan./jun. 2017. Disponível em: <https://doi.org/10.29051/rel.v3.n1.jan-jun.2017.9434>. E-ISSN: 2447-3529.

Submetido em: $13 / 02 / 2017$

Aprovado em: 27/08/2017 